Agronomía Costarricense 41(1): 33-51. ISSN:0377-9424 / 2017

www.mag.go.cr/rev_agr/index.html www.cia.ucr.ac.cr

\title{
USO POTENCIAL DE LIXIVIADOS Y TÉS DE VERMICOMPOST EN EL CONTROL DEL OJO DE GALLO DEL CAFETO Mycena citricolor
}

\author{
Karen Zamora*, Leida Castro ${ }^{*}$, Amy Wang ${ }^{* *}$, Luis Felipe Arauz ${ }^{* *}$, Lidieth Uribe $^{1 / *}$
}

Palabras clave: Ojo de gallo; Mycena citricolor; té de vermicompost; lixiviados de vermicompost. Keywords: American leaf spot of coffee; Mycena citricolor; vermicompost tea; vermicompost lecheates.

Recibido: 10/11/16

RESUMEN

El objetivo de este trabajo fue evaluar el efecto de tés y lixiviados de vermicompost obtenidos a partir de diferentes materiales de origen animal y vegetal, sobre la supresión del hongo $M$. citricolor en hojas de cafeto (Coffea arabica) en condiciones de laboratorio. A las hojas de cafeto se les aplicó tés de vermicompost de diferentes estiércoles, de broza de café y de una mezcla de lixiviados de vermicompost de broza de café y estiércol bovino, previo a la inoculación con el hongo M. citricolor. Se evaluó la incidencia (porcentaje de hojas enfermas) y severidad (porcentaje de área foliar dañada), el número de lesiones con gemas y de estructuras reproductivas del hongo (gemas). Se observó diferencias dentro de cada grupo de abono, así, cuando se aplicaron tés a base de vermicompost de estiércoles, se encontró que el té de vermicompost de estiércol caprino favoreció el desarrollo de los síntomas de la enfermedad, pues presentó un 16,5\% más de área foliar dañada y un mayor número de lesiones con gemas, comparado con el tratamiento testigo; por el contrario el tratamiento con té de vermicompost de estiércol bovino presentó un $50 \%$ menos de hojas enfermas que el tratamiento

1 Autora para correspondencia. Correo electrónico: lidieth.uribe@ucr.ac.cr

* Universidad de Costa Rica, Laboratorio de Microbiología Agrícola, Centro de Investigaciones Agronómicas, Costa Rica.
Aceptado: 27/01/17

\section{ABSTRACT}

Potential use of vermicompost leachates and tea in the control of the American leaf spot of coffee Mycena citricolor. The aim of this study was to evaluate the effect of vermicompost teas and vermicompost leachates from different material of animal and plant origin, on the suppression of $M$. citricolor in coffee leaves (Coffea arabica) under laboratory conditions. Teas from vermicompost of different manures, and coffee pulp, and a mixed of vermicompost leachates from coffee pulp and cattle manure were applied to coffee leaves, prior to inoculation with $M$. citricolor. Incidence (percentage of affected leaves) and severity (percent of leaf area damage), number of gem producing lesions and fungal reproductive structures (gems) were evaluated. Differences were observed within each organic waste group, thus, when manure-based vermicompost teas were applied, the one based on goat manure resulted in $16.5 \%$ more foliar area damage and a greater number of sporulated lesions compared to the control treatment. On the other hand, the treatment with bovine manure tea showed a 50\% less affected leaves that the control treatment and no sporulated lesions. The use of

** Univeridad de Costa Rica, Centro de Investigación en Protección de Cultivos, Costa Rica. 
testigo y no presentó lesiones con gemas. El uso de tés de vermicompost de broza de café aumentó el desarrollo de la enfermedad con un porcentaje de hojas enfermas y del área foliar dañada superior al testigo en más de un $20 \%$. En el caso de los tratamientos con lixiviados de vermicompost, aquellos a base de vermicompost de broza, no presentaron lesiones con formación de gemas.

\section{INTRODUCCIÓN}

El cafeto es el cultivo perenne con mayor área sembrada (84 133 hectáreas) y constituye una de las principales actividades económicas en Costa Rica, especialmente para pequeños y medianos productores (Villegas 2011, INEC 2015). La producción anual es superior a los 2 millones de fanegas que representa el $11 \%$ del total de divisas generadas por el sector agropecuario. Junto con el té y las especies, ocupa el segundo puesto de importancia en las exportaciones, ya que genera 289 millones de dólares (ICAFE 2011b, PROCOMER 2015).

La enfermedad causada por Mycena citricolor (Berk y Curt) Sacc. conocida como "ojo de gallo", representa uno de los problemas que más afecta la producción de café en Costa Rica y Centroamérica (Vargas 2004). El principal daño es la defoliación, a pesar de que la planta no muere, disminuye notablemente el área fotosintética y causa un debilitamiento que favorece el desarrollo de otras enfermedades (Vargas et al. 1990).

Esta enfermedad se caracteriza por la formación de pequeñas manchas circulares u ovaladas, ligeramente hundidas, con un diámetro de 6-10 mm sobre las hojas. Las lesiones se inician como puntos café oscuro de borde indefinido, que al alcanzar su tamaño final presentan un borde coffee pulp teas increased percentage of affected leaves and leaf area damage over $20 \%$ compared to the control treatment. With respect to leachate vermicompost treatments, the ones based on coffee pulp showed no gem-producing lesions.

bien marcado, con poca o ninguna clorosis alrededor y pueden ser de color café claro, grisáceo o café rojizo, con apariencia papelosa y seca (López 1994). Cuando las lesiones se forman a lo largo de una vena principal, toman una forma alargada en el sentido de la vena y provocan epinastia en las hojas jóvenes. Las fructificaciones asexuales del hongo (cabecitas o gemas) se desarrollan sobre las lesiones y pueden encontrarse tanto en el haz como en el envés de las hojas, estas estructuras son las que permiten la diseminación del hongo en el campo (Carvajal 1939, Wang y Avelino 1999, González 2003).

En Costa Rica, se da un pico de infección entre setiembre y octubre, que corresponden a los meses de mayor precipitación. La enfermedad empieza a disminuir en diciembre y los niveles más bajos ocurren entre febrero y mayo, lo que coincide con la época más seca del año. Sin embargo, en algunas áreas, especialmente cerca de zonas boscosas, las condiciones de humedad permiten que la enfermedad continúe su desarrollo durante este periodo (Wang y Avelino 1999).

El ojo de gallo puede afectar seriamente cafetos que se encuentran en áreas frías, húmedas y muy sombreadas, en zonas con altitudes mayores de $650 \mathrm{msnm}$ con prevalencia de humedad relativa alta y temperaturas entre $19^{\circ} \mathrm{C}$ y $23^{\circ} \mathrm{C}$ (Echeverri 1997, Barquero 2007). Según 
las condiciones de humedad, el hongo puede alcanzar niveles de incidencia superiores a $40 \%$ y provocar una caída en el rendimiento de un 20-30\% en el mismo año de la epidemia (Chaves 1996). Bajo condiciones climáticas favorables y sin un manejo apropiado de la enfermedad, puede ocurrir la pérdida de un $60 \%$ de la cosecha presente y una reducción del $100 \%$ en el potencial productivo en el siguiente ciclo de producción, esto debido al agotamiento que sufren las plantas por la caída masiva de hojas atacadas por M. citricolor (ICAFE 2011a, Barquero 2012).

En Costa Rica, el combate tradicional consiste en la aplicación de fungicidas en la época lluviosa, que corresponde al periodo de mayor incidencia de la enfermedad (ICAFE 2011a). Sin embargo, la creciente necesidad de producir con prácticas amigables con el ambiente, hace del uso de abonos orgánicos una alternativa prometedora para el combate de esta enfermedad.

Los tés de compost y lixiviados de vermicompost son abonos líquidos que se aplican por aspersión foliar o al suelo, y han sido utilizados con éxito en el combate de algunas enfermedades de plantas. El té de compost es una infusión preparada a base de compost o vermicompost y agua, en una proporción que varía de 1:3 a 1:200 y que se incuba por un periodo de tiempo definido. El té se puede producir de forma anaeróbica o aeróbica, esta última mediante el burbujeo continuo de aire. Durante el proceso los microorganismos y nutrientes solubles del vermicompost son extraídos en el té (Hoitink et al. 1997, Scheuerell y Mahaffee 2002, Larco 2004, Scheuerell y Mahaffee 2004, Arancon et al. 2007, Al-Mughrabi et al. 2008, Castello et al. 2014).

Los tés de compost pueden ser enriquecidos con materiales como algas, proteínas de pescado, ácido húmico, polvo de roca, quitina coloidal o sustancias ricas en ésta como los residuos de camarón; estos aditivos se utilizan con el fin de aumentar los contenidos de nutrientes y microorganismos benéficos. Los tés actúan como un fungicida natural que contiene poblaciones de microorganismos, quelantes orgánicos y metabolitos (Hoitink et al. 1997, Scheuerell y Mahaffee 2002, Larco 2004, Scheuerell 2003, Scheuerell y Mahaffee 2004, Diánez et al. 2007, Al-Mughrabi et al. 2008, Fritz et al. 2012, Castello et al. 2014, Marin et al. 2014).

Se han encontrado resultados positivos del uso de tés para el combate de patógenos como Botrytis cinerea, Pythium ultimum, Venturia inaequalis, Alternaria solani, Verticillium dahliae, Sphaeroteca pannosa, Phytophthora infestans, P. capsici, P. parasitica, Fusarium oxysporum f. sp., lycopersici, Rhizoctonia solani, Sclerotinia minor, Sclerotium rolfsii, Didymella bryoniae, Podosphaera fusca, entre otros (Scheuerell y Mahaffee, 2002, Scheuerell 2003, Edwards et al. 2006, Al-Mughrabi et al. 2008, Marin et al. 2013, Marin et al. 2014, Castello et al. 2014), sin embargo, existen diferencias en la efectividad del té en el combate de patógenos, lo que se atribuye a variaciones en el método de preparación, compost utilizado, edad, tiempo de aereación, lote, población microbiana, prácticas de aplicación y patosistema evaluado (Hoitink et al. 1997, Scheuerell y Mahaffee, 2002, Scheuerell y Mahaffee 2004, Marin et al. 2013). Aunque algunos autores señalan mayor eficacia en tés de compost derivados de estiércol que de residuos vegetales (Scheuerell y Mahaffee 2002), existen informes de que los tés vegetales también son supresivos (Scheuerell 2003).

Entre los factores responsables de la supresión se señala la resistencia inducida, una mejor nutrición de la planta y la presencia de microorganismos antagonistas que por hiperparasitismo, antibiosis o competencia inhiben al hongo patógeno (Hoitink et al. 1997, Scheuerell y Mahaffee 2002, Scheuerell 2003, Scheuerell y Mahaffee 2004, Edwards et al. 2006, Al-Mughrabi et al. 2008, Marin et al. 2013, Castello et al. 2014).

Por otro lado, la adición de quitina durante el proceso de vermicompostaje o en la elaboración del té, podría favorecer el incremento de las poblaciones de microorganismos quitinolíticos con potencial como agentes de biocontrol de hongos fitopatógenos, ya que la pared celular de los mismos contiene quitina (Scheuerell 2003, 
Salazar et al. 2006, Sastoque et al. 2007), además, la degradación microbiana de la quitina puede aportar $\mathrm{N}$ para las plantas y microorganismos, generar compuestos nitrogenados tóxicos como el amoniaco y el ácido nitroso o inductores de los mecanismos de defensa de las plantas como los derivados del quitosano (Cohen 2001, Scheuerell 2003, Castro et al. 2011). El uso de la quitina comercial o los residuos de camarón para el combate de enfermedades radicales y foliares ha sido evaluado por varios autores (Osorio et al. 2004, Sastoque et al. 2007, Farfán y Gutiérrez 2009, Oka 2010, Castro et al. 2011). Se desconoce su efecto sobre Mycena citricolor.

Los lixiviados de vermicompost son abonos líquidos que contienen nutrientes, microorganismos y ácidos húmicos por lo que se han usado principalmente como fertilizantes orgánicos en diferentes cultivos. Se generan durante el proceso de vermicompostaje producto de la transformación de la materia orgánica al ser mezclada e ingerida por la lombriz, este material es drenado y recolectado para evitar la saturación de las camas. Los lixiviados se deben diluir al menos al 50\% antes de aplicarlos ya que pueden causar problemas de toxicidad por el alto contenido de sales (Ferruzi 1994, García et al. 2008, GutiérrezMiceli et al. 2008, Fortis et al. 2009, Garg y Gupta 2009, Nath et al. 2009, Arauz 2011, Preciado et al. 2011).

Según Litterick et al. (2004) los lixiviados se pueden utilizar para el combate de plagas y enfermedades, puesto que tienen una gran abundancia y diversidad de microorganismos benéficos. Así mismo, contienen sustancias antimicrobianas que inhiben el crecimiento de hongos patógenos (Gutiérrez-Miceli et al. 2008). No se ha investigado su capacidad para suprimir el ojo de gallo.

El objetivo de este trabajo fue evaluar tés y lixiviados de vermicompost obtenidos a partir de diferentes materiales de origen animal y vegetal, y su efecto sobre la supresión del hongo $M$. citricolor (Berk y Curt) Sacc en hojas de cafeto (Coffea arabica L.) en condiciones de laboratorio.

\section{MATERIALES Y MÉTODOS}

La investigación se realizó en el Laboratorio de Microbiología Agrícola del Centro de Investigaciones Agronómicas de la Universidad de Costa Rica.

Se prepararon vermicompostas a partir de estiércol equino, bovino y caprino, broza de café y broza de café con residuos de camarón y se recolectaron los lixiviados. Los abonos de origen animal fueron proporcionados por la Estación Experimental Alfredo Volio Mata de la Universidad de Costa Rica; ubicada en la zona de Ochomogo, Cartago; y los abonos de origen vegetal fueron facilitados por la Cooperativa Coopepalmares localizada en Palmares, Alajuela.

\section{Preparación de los tés de vermicompost}

Se colocaron $100 \mathrm{~g}$ del vermicompost en una bolsa hecha con una malla, la cual se ubicó dentro de un recipiente de plástico sin tapa con capacidad para 10 litros y se agregaron 5 litros de agua desionizada con $10 \mathrm{ml}$ de melaza. La mezcla se incubó bajo aeración constante por 24 horas con una bomba de pecera para 19 litros. A los tratamientos que llevaban quitina al $0,4 \%$, se agregaron $20 \mathrm{~g}$ de quitina comercial marca Sigma Aldrich (Shrim Shell, practical grade) en el recipiente junto con los otros ingredientes (Rodríguez y Morgan 1987).

\section{Preparación de las cámaras húmedas}

La cámara húmeda estuvo conformada por una bandeja de plástico transparente con tapa y con capacidad para $4702,5 \mathrm{~cm}^{3}$, dentro de la cual se colocó una capa de papel toalla estéril sobre la que se dispusieron las hojas de cafeto. El papel toalla se mantuvo humedecido con agua estéril para conservar una atmósfera con humedad relativa alta necesaria para el desarrollo de la enfermedad.

\section{Cepa de Mycena citricolor}

Se utilizó la cepa de Mycena citricolor (Berk y Curt) Sacc "My 59”, proporcionada por 
el Instituto Costarricense del Café (ICAFE). La reproducción del hongo in vitro, se realizó según la metodología propuesta por González (2003). Se transfirió una sección de $6 \mathrm{~mm}$ de diámetro de un cultivo de 12 días del hongo. Se colocaron 4 círculos con micelio en cada placa de Petri con medio de cultivo PDA (papa-dextrosa-agar) acidificado con ácido láctico al 10\%. Las placas de Petri inoculadas se colocaron en una caja de plástico en un sitio con iluminación natural y a temperatura ambiente. La esporulación del hongo se produjo alrededor de 2 semanas después.

\section{Plantas de cafeto}

Se utilizaron hojas de plantas de cafeto (Coffea arabica L.) de la variedad Catuaí Rojo de un año, proporcionadas por la Cooperativa Coopepalmares. Se mantuvieron en el invernadero del Laboratorio de Microbiología Agrícola de la Universidad de Costa Rica durante el periodo de realización de los ensayos. Las plantas se trasplantaron a potes de plástico (número 400) con suelo proveniente de la misma zona, se fertilizaron con $6 \mathrm{~g}$ de 10-30-10 a los 7 días después del trasplante y a los 2 meses. Además se complementó la nutrición con 2 aplicaciones foliares del fertilizante fórmula 20-20-20 (Nitrógeno, Potasio y Fósforo) y elementos menores de una marca seleccionada. La primera aplicación se hizo a los 30 días después del trasplante y la segunda una semana después.

\section{Análisis de la composición química y microbiológica de los vermicompost, tés de vermicompost y lixiviados}

Se determinó la composición química y microbiológica de los vermicompost, lixiviados y tés de compost. Se tomó una muestra de 500 g de cada uno de los vermicompost en una bolsa plástica, y una muestra de un litro de cada uno de los diferentes tés y lixiviados en una botella de plástico. Todas las muestras se llevaron al Laboratorio de Suelos y Foliares del Centro de Investigaciones Agronómicas de la Universidad de Costa Rica para hacer un análisis químico completo que incluía los contenidos totales de $\mathrm{N}, \mathrm{P}, \mathrm{K}, \mathrm{Ca}, \mathrm{Mg}$, $\mathrm{S}, \mathrm{Fe}, \mathrm{Cu}, \mathrm{Mn}, \mathrm{Zn}$ y B, el contenido de humedad y valor del $\mathrm{pH}$, según la metodología propuesta por Soil and Plant Analysis Council (1998).

Además, se tomó una muestra de $500 \mathrm{~g}$ de cada uno de los vermicompost y $100 \mathrm{ml} \mathrm{de}$ lixiviados diluidos al $10 \%$ y tés de vermicompost para determinar mediante recuento en plato el número de bacterias y actinomicetes, hongos, levaduras y lactobacilos en los medios Albuminato de sodio, PDA, Extracto de Malta y MRS, respectivamente (Wollum 1982, Lorch et al. 1995, Rodríguez et al. 2005).

A los vermicompost se les determinó la estabilidad, para ello se ajustó el contenido de humedad al $70-85 \%$ y se pesaron $20 \mathrm{~g}$ del abono por duplicado en beakers que se colocaron en una jarra de incubación. Dentro de la jarra se colocó un recipiente con $10 \mathrm{ml}$ de agua y otro con 20 $\mathrm{ml}$ de $\mathrm{NaOH} 1 \mathrm{M}$. Se prepararon 4 blancos en 4 beakers que contenían $20 \mathrm{ml}$ de $\mathrm{NaOH} 1 \mathrm{M}$ en la jarra. Los envases se cerraron herméticamente y

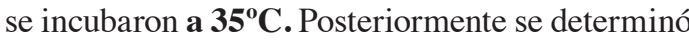
por titulación con $\mathrm{HCL} 0,5 \mathrm{M}$ la cantidad de $\mathrm{CO}_{2}$ absorbida por el $\mathrm{NaOH}$. Se determinó a cada vermicompost el peso seco y la cantidad de sólidos volátiles en la muestra, los resultados se reportaron como $\mathrm{mg} \mathrm{CO}_{2} \mathrm{~g}^{-1} \mathrm{SV}^{-1} \mathrm{~d}^{-1}$ (TMECC 2002).

\section{Evaluación de la capacidad de supresión del ojo de gallo}

Se hicieron 3 ensayos para evaluar la capacidad de los tés y lixiviados de vermicompost para suprimir la enfermedad del ojo de gallo. En el primer ensayo se evaluó el efecto supresor de tés a base de vermicompost de estiércoles sobre el desarrollo de M. citricolor inoculado en hojas de cafeto. Se utilizaron 7 tratamientos, la aplicación de té de vermicompost de estiércol equino, té de vermicompost de estiércol bovino, té de vermicompost de estiércol caprino, té de vermicompost de estiércol equino con quitina, té de vermicompost de estiércol bovino con quitina, té de vermicompost de estiércol caprino con quitina y como testigo, se utilizó agua desionizada estéril. 
En el segundo ensayo se evaluó el efecto de la aplicación de los tés de vermicompost a base de broza y su enriquecimiento con quitina y/o residuos de camarón, sobre el desarrollo del ojo de gallo mediante la aplicación de los siguientes tratamientos: té de vermicompost de broza de café, té de vermicompost de broza de café con quitina; té de vermicompost de broza de café enriquecido con camarón y té de vermicompost de broza de café enriquecido con camarón y con quitina y un testigo, para un total de 5 tratamientos.

En el tercer ensayo se evaluó el efecto de la aplicación de los lixiviados de vermicompost sobre el desarrollo del ojo de gallo. Los tratamientos utilizados fueron: lixiviados de vermicompost a base de broza de café, lixiviado de broza de café enriquecida con residuos de camarón, lixiviados de vermicompost de estiércol bovino y un testigo, para un total de 4 tratamientos. Los lixiviados se aplicaron diluidos al $10 \%$.

Se utilizó un diseño experimental irrestricto al azar, la unidad experimental estuvo compuesta por 5 hojas de cafeto dispuestas en una cámara húmeda. Se utilizaron 10 repeticiones por tratamiento. A cada unidad experimental se le roció $10 \mathrm{ml}$ del tratamiento o agua desionizada estéril (en el caso del testigo), para humedecer totalmente las hojas. Se realizó una única aplicación 24 horas antes de la inoculación de las hojas de cafeto con $M$. citricolor; ya que en ensayos preliminares se observó que la población de bacterias inoculadas disminuía significativamente a las 48 horas. Cinco de las repeticiones de cada tratamiento se sacrificaron a las 24 horas a fin de determinar el efecto de la aplicación de los abonos sobre la población microbiana en la superficie de la hoja. Las 5 repeticiones restantes se inocularon con el patógeno.

En el primer ensayo en cada hoja se hicieron 2 puntos de inoculación en los cuales se colocaron 5 cabecitas de $M$. citricolor en cada uno, en los ensayos 2 y 3 se realizaron 3 puntos de inoculación por hoja.

\section{Variables evaluadas}

Se evaluó mediante recuento en plato la cantidad de bacterias, actinomicetes, hongos, levaduras y lactobacilos a las 24 horas en 5 de las repeticiones de cada tratamiento, para ello se tomaron las 5 hojas de cafeto que conformaban la unidad experimental y se realizó el recuento microbiológico, las hojas se colocaron en una bolsa plástica transparente estéril con $90 \mathrm{ml}$ de agua desionizada estéril. Luego se colocaron dentro del Stomacher ${ }^{\circledR} 400$ Circulator por un periodo de 3 minutos y a 300 revoluciones por minuto. Se realizaron diluciones seriadas y se utilizaron los medios albuminato de sodio, PDA, extracto de malta y MRS (Wollum 1982, Lorch et al. 1995, Rodríguez et al. 2005). Los datos de las Unidades Formadoras de Colonias (UFC) de los recuentos microbiológicos se transformaron con el Log10, previo al análisis de varianza y se procedió a separar las medias con la prueba LSD Fisher $(p<=0,05)$ con el programa Infostat.

Se evaluó el número de hojas con lesiones (incidencia), número de lesiones totales, número de lesiones con gemas y número de estructuras reproductivas (cabecitas o gemas), 2 veces por semana durante 3 semanas. Las datos obtenidos se transformaron con la "transformación de promedios alineados" y se analizaron con la prueba no paramétrica de Kruskall Wallis para una $\mathrm{p}<0,10$ (Wobbrock et al. 2011).

En la última evaluación se determinó porcentaje del área foliar dañada (severidad). Para la obtención del área de la hoja y el área de la hoja con lesiones, se tomó una fotografía a cada una de las hojas junto con una referencia de longitud (regla de $30 \mathrm{~cm}$ ) y se analizaron con el programa Image J. Los datos se analizaron por medio del análisis de varianza y se procedió a separar las medias con la prueba LSD Fisher $(\mathrm{p}<=0,05)$ con el programa Infostat (Di Rienzo et al. 2011).

\section{RESULTADOS Y DISCUSIÓN}

\section{Características químicas y biológicas de los vermicompost, tés y lixiviados de vermicompost}

Existe variabilidad en la composición química de los vermicompost utilizados en la preparación de los tés y lixiviados (Cuadro 1), estas 
Cuadro 1. Caracterización química y microbiológica de los vermicompost utilizados para la preparación de tés y lixiviados.

\begin{tabular}{|c|c|c|c|c|c|}
\hline \multirow[b]{2}{*}{ Análisis } & \multicolumn{5}{|c|}{ Vermicompost } \\
\hline & $\begin{array}{l}\text { Estiércol } \\
\text { equino }\end{array}$ & $\begin{array}{l}\text { Estiércol } \\
\text { bovino }\end{array}$ & Estiércol caprino & Broza & $\begin{array}{l}\text { Broza } \\
\text { camarón }\end{array}$ \\
\hline $\mathrm{N} \%$ & 1,90 & 2,00 & 1,43 & 4,59 & 4,36 \\
\hline $\mathrm{P} \%$ & 0,95 & 1,60 & 1,51 & 0,38 & 0,58 \\
\hline $\mathrm{K} \%$ & 1,79 & 1,75 & 2,22 & 4,08 & 5,07 \\
\hline $\mathrm{Ca} \%$ & 1,40 & 2,33 & 2,65 & 2,39 & 3,18 \\
\hline $\mathrm{Mg} \%$ & 0,54 & 0,75 & 0,73 & 0,38 & 0,43 \\
\hline $\mathrm{S} \%$ & 0,34 & 0,37 & 0,42 & 0,58 & 0,61 \\
\hline $\mathrm{Fe}\left(\mathrm{mg} \cdot \mathrm{kg}^{-1}\right)$ & 5497 & 1929 & 12619 & 11481 & 11432 \\
\hline $\mathrm{Cu}\left(\mathrm{mg} \cdot \mathrm{kg}^{-1}\right)$ & 60 & 101 & 82 & 76 & 79 \\
\hline $\mathrm{Zn}\left(\mathrm{mg} \cdot \mathrm{kg}^{-1}\right)$ & 345 & 267 & 486 & 139 & 178 \\
\hline $\operatorname{Mn}\left(\mathrm{mg} \cdot \mathrm{kg}^{-1}\right)$ & 397 & 314 & 521 & 517 & 494 \\
\hline B (mg.kg-1) & 20 & 13 & 39 & 110 & 108 \\
\hline $\mathrm{pH}$ & 8,4 & 8,9 & 9,2 & 9,8 & 9,8 \\
\hline Porcentaje de humedad $\%$ & 80 & 80 & 73 & 55 & 58 \\
\hline Estabilidad $\left(\mathrm{mgCO}_{2} \mathrm{~g}^{-1} \mathrm{SV}^{-1} \mathrm{t}^{-1}\right)$ & 2,5 & 4,3 & 5,3 & 0,4 & 2,8 \\
\hline Bacterias (LogUFC. $\left.\mathrm{g}^{-1}\right)$ & 8,8 & 9,0 & 8,8 & 7,4 & 7,7 \\
\hline Actinomicetes $\left(\log U F C \cdot \mathrm{g}^{-1}\right)$ & 8,2 & 6,9 & 8,7 & 6,6 & 7,0 \\
\hline Hongos (LogUFC. $\left.\mathrm{g}^{-1}\right)$ & 4,5 & 4,1 & 5,0 & 4,9 & 6,0 \\
\hline Levaduras $\left(\log U F C . \mathrm{g}^{-1}\right)$ & 5,4 & 5,9 & 6,1 & 5,3 & 5,7 \\
\hline Lactobacilos (LogUFC. $\left.\mathrm{g}^{-1}\right)$ & 7,3 & 7,2 & $<4,0$ & 6,9 & 6,6 \\
\hline
\end{tabular}

diferencias se deben a las condiciones de elaboración, materia prima, proporción del residuo y estado de descomposición del material (Durán y Henríquez 2007, Artavia et al. 2010). Los vermicompost a base de broza de café tuvieron un mayor contenido de N, K y B, y un menor contenido de $\mathrm{P}$ y $\mathrm{Zn}$ que los elaborados con estiércoles.

El pH varió de 8,4 a 9,8 (Cuadro 1), los vermicompost a base de estiércol presentaron un $\mathrm{pH}$ más bajo que el mostrado por los de broza. Fortis et al. (2009) y Otero (2010) encontraron valores similares de $\mathrm{pH}$ en vermicompost de estiércoles, mientras que Durán y Henríquez (2007) y Siles (1997) obtuvieron para un vermicompost de broza de café pH neutros. En términos generales, el $\mathrm{pH}$ del vermicompost tiende a ser alcalino debido a la secreción de carbonato cálcico por las glándulas de Morren de la lombriz (Bollo 1999), además, los estiércoles presentan generalmente $\mathrm{pH}$ básico por liberar nitrógeno en forma de urea, que se descompone y forma amoniaco (MorenoCaselles et al. 2002), así mismo, durante el proceso de descomposición de la broza se generan $\mathrm{pH}$ alcalinos. Si bien las lombrices operan eficientemente a un pH entre 5 y 9, un rango de 7,5 a 8,0 es considerado óptimo (Garg y Gupta 2009).

El porcentaje de humedad estuvo entre $55 \%$ y $80 \%$ y fue mayor en los vermicompost de 
estiércol que en los de broza, lo que coincide con lo observado por Artavia et al. (2010) al evaluar abonos de origen vegetal y animal. Los vermicompost utilizados clasificaron como estables y muy estables (TMECC 2002), la menor actividad la presentó el vermicompost de broza (Cuadro 1). Artavia et al. (2010) reportó valores de 1,1 y 7,1 $\mathrm{mgCO}_{2} \mathrm{~g}^{-1} \mathrm{SV}^{-1} \mathrm{~d}^{-1}$ para vermicompost de broza y de estiercol bovino respectivamente.

Las poblaciones microbianas presentes en los vermicompost se ven influenciadas por la materia prima utilizada, las transformaciones de los desechos al ser mezclados e ingeridos por la lombriz, la inoculación con la flora microbiana presente en la misma y los cambios en el pH (Domínguez et al. 1997, Bollo 1999, Durán y Henríquez 2007, Uribe et al. 2009). En este estudio las bacterias dominaron las poblaciones de microorganismos cultivables (Cuadro 1), encontrándose una mayor cantidad en los abonos de estiércoles que en los obtenidos a partir de broza. Scheuerell (2003) indica que es posible encontrar en algunos compost de estiércoles una mayor población de microorganismos que en los de residuos vegetales debido a la alta biomasa microbiana presente en los estiércoles. Por otro lado, el menor número de lactobacilos se encontró en el vermicompost caprino $\left(<4,0 \log 10\right.$ UFC. ${ }^{-1}$, dilución más baja evaluada), mientras que los valores más altos de hongos se obtuvieron en el abono enmendado con residuos de camarón.

Cuando se evaluó la composición química de los tés de vermicompost (Cuadro 2), se observó el mayor contenido de $\mathrm{N}$ en el té de vermicompost de broza con camarón y el menor en el té de vermicompost de estiércol caprino. La concentración de $\mathrm{K}$ se relacionó en los tés sin quitina con el contenido de este elemento en los vermicompost ( $\left.\mathrm{y}=76,838 \mathrm{x}, \mathrm{R}^{2}=0,9446\right)$. El Ca varió de 38 a 102 en los tés a base de estiércol, y en los tés de origen vegetal, solo logró detectarse en la broza con quitina $\left(10 \mathrm{mg} \cdot \mathrm{ml}^{-1}\right)$. Los elementos $\mathrm{P}, \mathrm{Mg}, \mathrm{Cu}, \mathrm{Zn}$ y $\mathrm{Mn}$ no se encontraron en los tés de vermicompost mientras que el S, Fe y B se observaron en pequeñas cantidades y únicamente en algunos de los tés. El pH varió de 5,3 a 7,2. En términos generales, el contenido de nutrientes presente en los tés de vermicompost fue más bajo que el obtenido por Preciado et al. (2011) en un té preparado con un vermicompost comercial. 


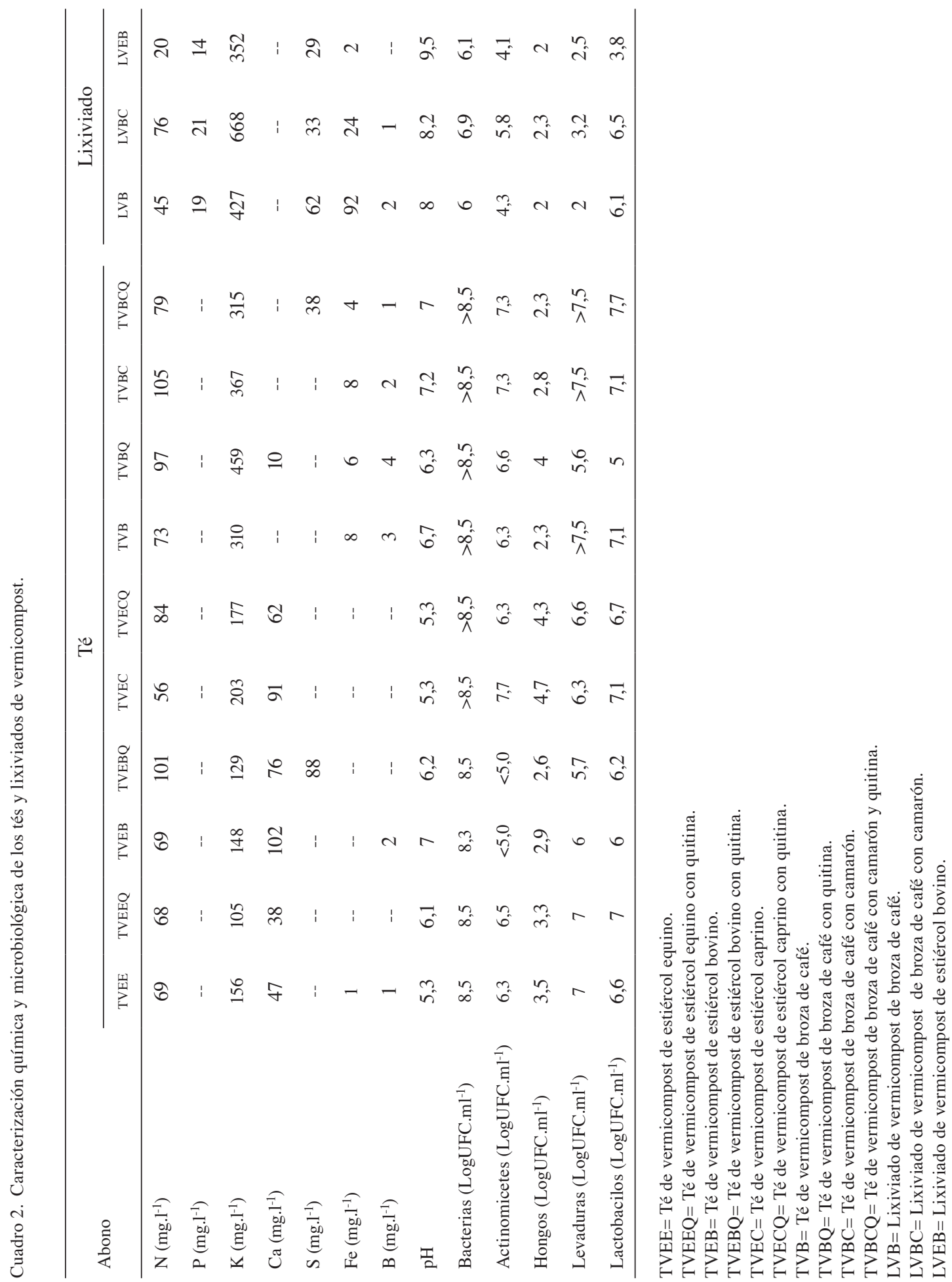


Durante el proceso de elaboración del té, a medida que los materiales son descompuestos por los microorganismos que los utilizan como fuente de energía en el caso del C o para la formación de proteínas y crecimiento celular como el N, la biomasa microbiana aumenta, por lo que los contenidos de $\mathrm{N}$ y $\mathrm{P}$ disponibles se reducen al ser inmovilizados, ya que los microorganismos actúan como sumidero y fuente importante de nutrimentos como el C, N y P (Paul y Clark 1996). Un caso similar puede ocurrir con el Mg, $\mathrm{K}$ y S, lo cual explicaría por qué algunos elementos no se detectaron en los tés. Así mismo el $\mathrm{pH}$ disminuye, lo que afecta las poblaciones microbianas y la solubilidad de los elementos. Por otro lado, la adición de quitina, material rico en nitrógeno, incrementó el contenido de este elemento en el té de vermicompost de estiércol bovino, caprino y en el de vermicompost de broza, mientras que los contenidos de $\mathrm{K}$ y Ca se redujeron en los tés de estiércoles a los que se adicionó quitina, probablemente el aporte de $\mathrm{N}$ propició la utilización de estos elementos por la flora microbiana.

Fritz et al. (2012) encontraron que el número de microorganismos en los tés aumenta durante el proceso de extracción y que se ve afectado por la adición del sustrato. En todos los tés se observa que las bacterias constituyen el grupo más importante de microorganismos (mayor a $\log 8,3$ UFC.ml $^{-1}$ ), esto se debe a su alta concentración en los vermicompost y a su capacidad competitiva en la presencia de sustratos fácilmente degradables, lo que concuerda con lo indicado por Scheuerell y Mahaffee (2004) al estudiar tés de compost con diferentes aditivos. La población de bacterias fue superior al rango de $\log$ 6,8 a $\log$ 7,7 UFC. $\mathrm{ml}^{-1}$ reportado por Mansour y El-sayed (2011) en tés de compost preparados a partir de una mezcla de estiércoles animales con granza de arroz y al 5,16 a 8,01 Log UFC.ml ${ }^{-1}$ observado por Castello et al. (2014). $\mathrm{Si}$ bien los lactobacilos presentaron números menores a $\log 4,0 \mathrm{UFCg}^{-1}$ en el vermicompost caprino, probablemente el cambio en las condiciones ambientales al hacer el extracto (por ej., la disminución del $\mathrm{pH}$ ) favoreció su incremento a 7,1 Log UFC.ml-1. Así, la preparación del té constituye un factor selectivo para las poblaciones de microorganismos.

Los actinomicetes se encontraron dentro del rango de 5,8 a 6,8 Log10 (UFC.ml-1 ${ }^{-1}$ ) obtenido por Mansour y El-sayed (2011) con excepción de los tés de vermicompost de estiércol bovino con y sin quitina, que presentaron un valor menor de 5,0 Log10 UFC.ml- ${ }^{-1}$ (dilución más baja evaluada), el bajo contenido de estos organismos se debe a su menor cantidad en el vermicompost de estiércol bovino, a que crecen lentamente en comparación con las bacterias y a que en presencia de sustratos fácilmente degradables su número disminuye por la presión de competencia con otros grupos (Lazcano et al. 2008, Farfán y Gutiérrez 2009). Al igual que lo indicado por Scheuerell y Mahaffee (2004) las poblaciones de hongos fueron menores en los tés con y sin aditivos que en los vermicompost. Los hongos son aeróbicos, crecen lentamente y compiten con dificultad en medios líquidos con fuentes de $\mathrm{C}$ fácilmente disponibles.

Con respecto a los lixiviados (Cuadro 1), el mayor contenido de $\mathrm{N}$ y $\mathrm{K}$ se encontró en el lixiviado de broza de café con residuos de camarón; mientras que el lixiviado de estiércol bovino mostró los menores valores de dichos elementos. El mayor contenido de $\mathrm{S}$ y Fe se presentó en el lixiviado de vermicompost de broza. El $\mathrm{pH}$ de todos los lixiviados fue superior al 7,8 reportado por García et al. (2008) en un lixiviado de vermicompost de estiércol bovino.

Los lixiviados presentaron valores de bacterias y levaduras menores que los observados en los tés de vermicompost. Estos resultados pueden deberse a los altos valores de $\mathrm{pH}$ de estos abonos y a que se utilizaron lixiviados diluidos $1 / 10$. La mayor cantidad de microorganismos cultivables se encontró en el lixiviado de broza enriquecido con camarón lo que se debe probablemente a una mayor fuente de sustratos en este tratamiento. El lixiviado de vermicompost de estiércol bovino presentó una población de lactobacilos 1000 veces menor que los lixiviados de broza lo que atribuimos al alto $\mathrm{pH}$ presente en este lixiviado. 
Efecto de la aplicación de tés de vermicompost a base de estiércoles sobre las hojas de cafeto

Se encontró una población residente de microorganismos cultivables sobre las hojas de cafeto, según se evidencia en el tratamiento testigo (Figura 1), lo que obedece a que en el filoplano hay numerosos micrositios que permiten el establecimiento y desarrollo de una población epífita compuesta primordialmente por bacterias, actinomicetes y hongos filamentosos (Blakeman y Fokkema 1982, Arauz 2011). Los resultados del estudio coinciden con lo observado por Mora (1987) quien señala a las bacterias como el grupo más numeroso en la hoja de cafeto, resultado que atribuye al crecimiento rápido y habilidad de estos organismos para utilizar diferentes nutrimentos.

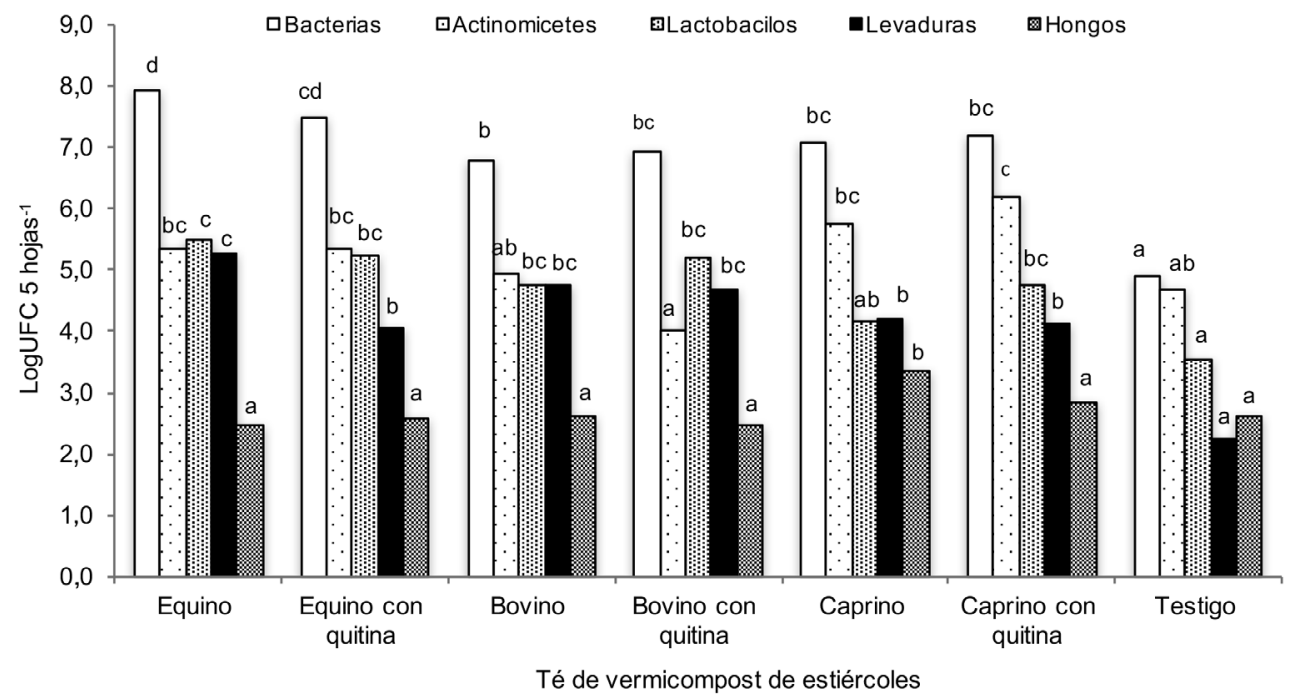

Fig. 1. Población de microorganismos en hojas de cafeto tratadas con tés de vermicompost de excretas animales.

La aplicación de los tés incrementó el número de bacterias y levaduras en la superficie de las hojas, este aumento se debe a la adición de los microorganismos presentes en el té y a los nutrientes que sirven de sustrato tanto a los microorganismos inoculados (Al-Mughrabi et al. 2008), como a los que se encuentran naturalmente sobre las hojas. Los microorganismos compiten por nutrientes y la colonización del filoplano, y son favorecidos los que logren usar los recursos más eficientemente y enfrentar interacciones como la inhibición, antagonismo, depredación y antibiosis que influyen en la dinámica poblacional (Arauz 2011, Marin et al. 2013).

Los lactobacilos aumentaron en todos los tratamientos excepto en las hojas aplicadas con el té de vermicompost de estiércol caprino a pesar del alto número de microorganismos presentes en el mismo. Las hojas inoculadas con el té de origen equino presentaron el valor más alto de bacterias, lactobacilos y levaduras, mientras que la adición del té de vermicompost de estiércol caprino con quitina aumentó significativamente la población de actinomicetes. El mayor número de hongos se encontró en el tratamiento al que se aplicó té de vermicompost de estiércol caprino, lo que coincidió con la concentración más alta de estos organismos en el té (Figura 1, Cuadro 2).

Al estudiar el efecto de los tés sobre la enfermedad, se encontró que las hojas a las que se aplicó el té de vermicompost de estiércol caprino presentaron una incidencia mayor que 
las inoculadas con los tés de vermicompost de estiércol equino, bovino, bovino con quitina y caprino con quitina (Cuadro 3), y una severidad significativamente mayor que el testigo y demás tratamientos. El uso de este té aumentó significativamente el número de hojas con lesión, y número de cabecitas (Cuadro 3, Figura 2) con respecto al tratamiento té de vermicompost de estiércol

Cuadro 3. Efecto de la aplicación de los tés de vermicompost de estiércoles sobre el desarrollo de la enfermedad en hojas de cafeto.

\begin{tabular}{lccccc}
\hline $\begin{array}{l}\text { Té vermicompost } \\
\text { estiercol }\end{array}$ & $\begin{array}{l}\text { Incidencia* } \\
\%\end{array}$ & $\begin{array}{l}\text { Severidad* } \\
\%\end{array}$ & Lesiones** & $\begin{array}{l}\text { Lesiones con } \\
\text { gemas** }\end{array}$ & Gemas/lesión** \\
\hline Equino & $20 \mathrm{a}$ & $2,6 \mathrm{a}$ & $7,0 \mathrm{a}$ & $1,4 \mathrm{abc}$ & $23,4 \mathrm{ab}$ \\
Equino quitina & $40 \mathrm{ab}$ & $6,6 \mathrm{a}$ & $12,6 \mathrm{a}$ & $1,8 \mathrm{bc}$ & $10,4 \mathrm{~b}$ \\
Bovino & $16 \mathrm{a}$ & $1,3 \mathrm{a}$ & $2,0 \mathrm{a}$ & $0,0 \mathrm{a}$ & $0,0 \mathrm{a}$ \\
Bovino quitina & $28 \mathrm{a}$ & $4,2 \mathrm{a}$ & $8,0 \mathrm{a}$ & $1,8 \mathrm{bc}$ & $14,2 \mathrm{~b}$ \\
Caprino & $60 \mathrm{~b}$ & $19,0 \mathrm{~b}$ & $24,2 \mathrm{a}$ & $5,2 \mathrm{c}$ & $65,0 \mathrm{~b}$ \\
Caprino quitina & $20 \mathrm{a}$ & $1,3 \mathrm{a}$ & $5,8 \mathrm{a}$ & $1,0 \mathrm{abc}$ & $2,8 \mathrm{ab}$ \\
Testigo & $40 \mathrm{ab}$ & $2,5 \mathrm{a}$ & $6,8 \mathrm{a}$ & $0,4 \mathrm{ab}$ & $1,4 \mathrm{ab}$ \\
\hline
\end{tabular}

*Letras distintas indican diferencias significativas entre tratamientos $(\mathrm{p}<0,05)$.

**Letras distintas indican diferencias significativas entre tratamientos $(\mathrm{p}<0,10)$. Kruskall Wallis.
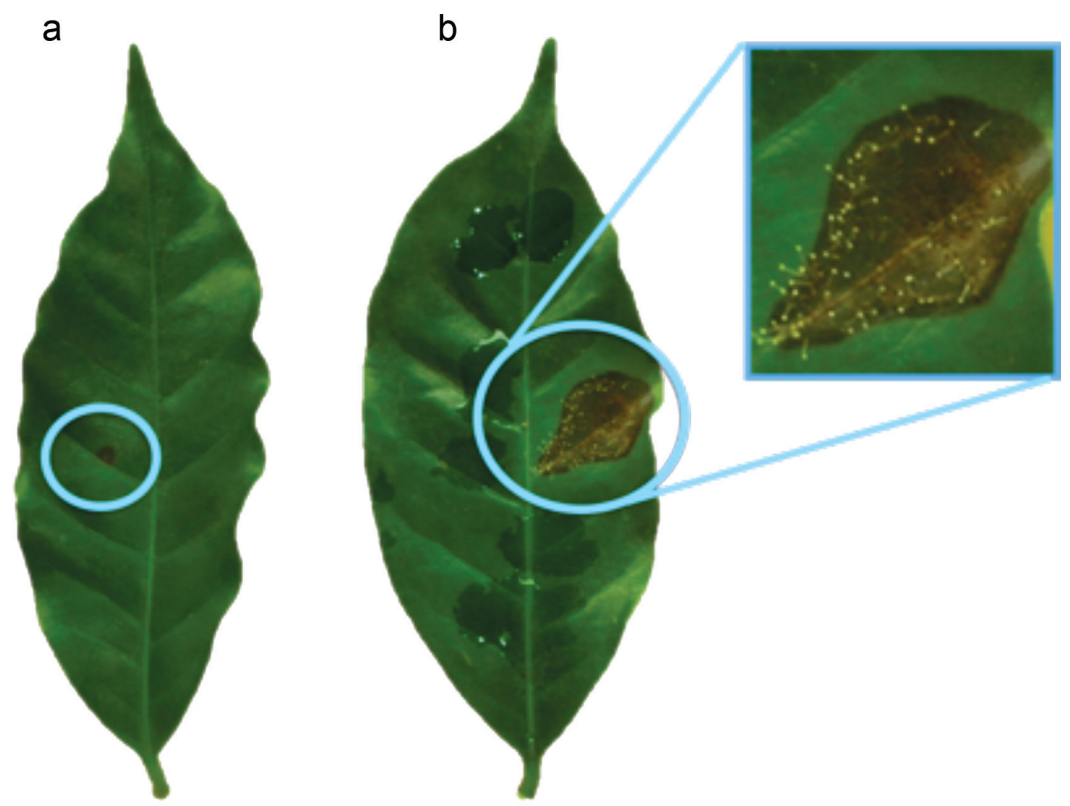

a. Lesión sin gemas en hojas tratadas con el té de vermicompost de estiércol bovino.

b. Lesión con gemas en hojas tratadas con el té de vermicompost de estiércol caprino.

Fig. 2. Efecto del té de vermicompost a base de estiércol sobre la producción de gemas en las lesiones causadas por $M$. citricolor a los 19 días de la aplicación. 
bovino, así como las lesiones con gemas en comparación con este mismo tratamiento y con el testigo (Cuadro 3). Como se mencionó anteriormente, el té de origen caprino presentó un número mayor de hongos que los otros tés (Cuadro 2), así como el mayor número de hongos en la superficie de la hoja (Figura 1). Al respecto varios autores señalan que el uso de aditivos podría neutralizar el potencial de control biológico del té al quedar nutrientes disponibles que pueden beneficiar el crecimiento de patógenos que posean una fase saprofítica eficiente, o por otro lado, suprimir la producción de antibióticos o la actividad parasítica de microorganismos antagonistas, al promover un metabolismo saprofítico (Hoitink et al. 1997, Scheuerell y Mahaffee 2004, Scheuerell y Mahaffee 2006). Es probable que el uso del té caprino favoreciera el crecimiento de los hongos presentes en el té y en la superficie de la hoja incluyendo al patógeno Mycena citricolor.

Por otro lado, la adición de quitina al té de vermicompost de estiércol caprino redujo la incidencia y severidad del ojo de gallo con respecto al tratamiento sin quitina. Este resultado podría deberse a cambios en la composición química o microbiana que redujeran el efecto conductivo de este té, el $\mathrm{N}$ aumentó de 56 a $84 \mathrm{mg} . \mathrm{l}^{-1}$ mientras que el K se redujo de 203 a 177 mg. $\mathrm{l}^{-1}$ y disminuyó significativamente la población de hongos sobre la hoja con respecto al té sin este aditivo.

El tratamiento al que se aplicó té de vermicompost de etiercol bovino tendió a presentar los menores valores en las variables evaluadas. Es posible que el resultado se deba a que este té mostró el mayor contenido de $\mathrm{Ca}$ y un $\mathrm{pH}$ más alto que los otros tés, según Vargas (1996), la aplicación de formulaciones de $\mathrm{Ca}$ a las hojas de cafeto tiene un efecto positivo en el combate de la enfermedad al contribuir a reducir el efecto del ácido oxálico. Se considera que el mecanismo patogénico del hongo es por medio de la producción de ácido oxálico, el cual captura el calcio estructural de los pectatos de las paredes celulares debilitándolas y facilitando la entrada de la hifa de M. citricolor (Rao y Tewari 1988, Tewari 1990). Resultados positivos con el uso de té de vermicompost de estiércol bovino fueron observados por Edwars et al. (2006) sobre Verticillium en tomate.

Cabe señalar que no se produjeron lesiones con gemas en el tratamiento al que se aplicó el té de vermicompost de estiércol bovino, este hallazgo es importante si se considera que las cabecitas son las estructuras de diseminación de $M$. citricolor en el campo, y que una forma de limitar su reproducción es a través de la disminución en la formación de estas estructuras de propagación. A partir de ese aspecto, se ha sugerido para el control de la enfermedad el uso de productos químicos que inhiban la formación de las gemas (Vargas et al. 1990, Wang y Avelino 1999, Wang y Arauz 1999, Barquero 2012, Granados 2015).

\section{Efecto del té de vermicompost a base de residuos de café sobre el ojo de gallo}

Con la aplicación de los diferentes tés de origen vegetal se elevó significativamente el número de bacterias, levaduras y lactobacilos en la superficie de las hojas, encontrándose la mayor población de bacterias y levaduras en las hojas inoculadas con el té de broza de café y el mayor contenido de hongos en las inoculadas con el té de broza con camarón y quitina (Figura 3).

La incidencia y severidad de la enfermedad del ojo de gallo, fue igual o mayor en las hojas inoculadas con los tés de vermicompost a base de broza, que en el tratamiento testigo (Cuadro 4). Un 80 a $92 \%$ de las hojas inoculadas con los tés presentaron lesiones, las cuales abarcaron de un 13,6 a un $24,3 \%$ del área de la hoja, mientras que en el tratamiento testigo se infectaron un $60 \%$ de las hojas y el área foliar dañada fue del 5,4\%. La mayor incidencia y severidad se encontró en el té de vermicompost de broza a pesar de que este tuviera las poblaciones más altas de bacterias y levaduras cultivables. Todos los tratamientos con tés presentaron un mayor número de lesiones que el testigo, mientras que el número de lesiones con gemas y el número de cabecitas por lesión no se diferenció del testigo. Los tratamientos inoculados con el té de vermicompost de broza de café con quitina y el té enriquecido con camarón y 


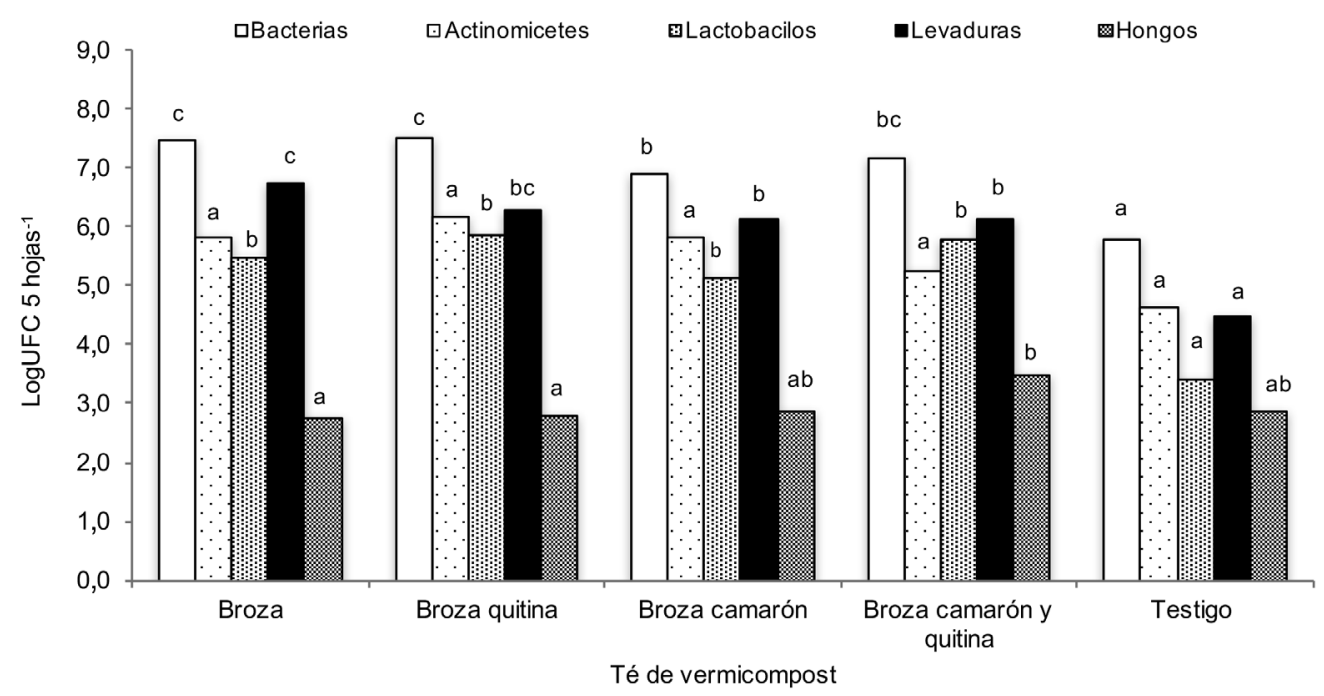

Fig. 3. Población de microorganismos en hojas de cafeto tratadas con tés de vermicompost de broza de café.

Cuadro 4. Efecto de la aplicación de los tés de vermicompost de broza sobre el desarrollo de la enfermedad en hojas de cafeto.

\begin{tabular}{|c|c|c|c|c|c|}
\hline Té de vermicompost & $\begin{array}{l}\text { Incidencia* } \\
\%\end{array}$ & $\begin{array}{l}\text { Severidad* } \\
\%\end{array}$ & Lesiones** & $\begin{array}{l}\text { Lesiones con } \\
\text { gemas** }\end{array}$ & Gemas/lesión** \\
\hline Broza & $92 \mathrm{~b}^{*}$ & $24,3 \mathrm{c}$ & $57,8 \mathrm{~b}$ & $2,4 \mathrm{a}$ & $12,6 \mathrm{a}$ \\
\hline Broza qutina & $88 \mathrm{~b}$ & $13,6 \mathrm{ab}$ & $48,8 \mathrm{~b}$ & $5,0 \mathrm{a}$ & $43,6 \mathrm{ab}$ \\
\hline Broza camarón & $80 \mathrm{ab}$ & $16,7 \mathrm{bc}$ & $51,6 \mathrm{~b}$ & $4,4 \mathrm{a}$ & $111,8 \mathrm{~b}$ \\
\hline Broza camarón qutina & $88 \mathrm{~b}$ & $22,3 \mathrm{bc}$ & $51,4 \mathrm{~b}$ & $5,2 \mathrm{a}$ & $95,4 \mathrm{~b}$ \\
\hline Testigo & $60 \mathrm{a}$ & 5,4 a & $22,0 \mathrm{a}$ & $3,2 \mathrm{a}$ & $47,8 \mathrm{ab}$ \\
\hline
\end{tabular}

*Letras distintas indican diferencias significativas entre tratamientos $(\mathrm{p}<0,05)$.

**Letras distintas indican diferencias significativas entre tratamientos $(\mathrm{p}<0,10)$. Kruskall Wallis

quitina presentaron el mayor número de cabecitas diferenciándose del tratamiento inoculado con el té de vermicompost de broza. Contrario a lo esperado, la adición de quitina a los tés de vermicompost no produjo un efecto supresivo sobre el patógeno, así como tampoco la alta cantidad de microorganismos inoculados en el té inhibió el desarrollo de la enfermedad.
Es probable que el uso de estos tés favoreciera la mojadura de la hoja y con ello el desarrollo de las lesiones, al permanecer una película de líquido por un mayor tiempo que en el tratamiento testigo. Granados (2015) indica que la aplicación de tratamientos que favorezcan la mojadura foliar puede beneficiar el desarrollo de la enfermedad. Según indica Barquero (2012), 
se necesita al menos 15 horas de mojadura foliar para el progreso de la enfermedad.

Por otro lado, el uso de aditivos como la melaza puede en algunos casos favorecer el crecimiento del patógeno. Al respecto, Scheuerell y Mahaffee (2004) encontraron que la adición de 0,01 a $0,30 \%$ de melasas a un té aereado redujo la supresión del mismo. Por su parte, Fritz et al. (2012) encontraron, mediante análisis de la comunidad microbiana por medio de la técnica de Electroforesis en gel de gradiente desnaturalizante (DGGE por sus siglas en inglés), que la composición microbiológica del té fue influenciada por la fuente de $\mathrm{C}$ utilizada, los autores identificaron la adición de $\mathrm{C}$ como un factor de gran relevancia. Debido a que los compost son materiales microbiológicamente diversos, los aditivos utilizados para producir té de compost actúan como fuerzas selectivas que afectan la diversidad microbiana (Scheuerell y Mahaffee 2002).

\section{Efecto de lixiviados de vermicompost sobre el ojo de gallo}

La adición de los lixiviados de vermicompost de broza aumentó significativamente la población de bacterias y lactobacilos en la superficie de la hoja, en comparación con el lixiviado de vermicompost de estiércol bovino y el testigo, lo que coincide con la mayor cantidad de lactobacilos encontrados en los lixiviados de vermicompost de broza que en el de origen bovino. Al respecto, se obtuvo una correlación negativa $\left(-0,97, \mathrm{r}^{2}=0,93\right)$ entre el $\mathrm{pH}$ del lixiviado y la población de lactobacilos en la hoja. Por otro lado, la población de actinomicetes fue significativamente mayor en las hojas de cafeto inoculadas con el lixiviado de vermicompost de broza con camarón, que en las inoculadas con el testigo y con el lixiviado de vermicompost de estiércol bovino (Figura 4). Únicamente el tratamiento con el lixiviado de origen bovino aumentó significativamente la población de levaduras con respecto al testigo, mientras que no se presentaron diferencias significativas en la población de hongos.

En este ensayo, la infección de las hojas de cafeto por $M$. citricolor fue más baja en el tratamiento testigo, comparado con los resultados obtenidos en las pruebas de supresión con los tés de vermicompost, a pesar de que se mantuvieron condiciones similares a las utilizadas para los otros ensayos. Esto se debe probablemente, a la pérdida de capacidad infectiva de los hongos mantenidos en laboratorio (Granados 2015).

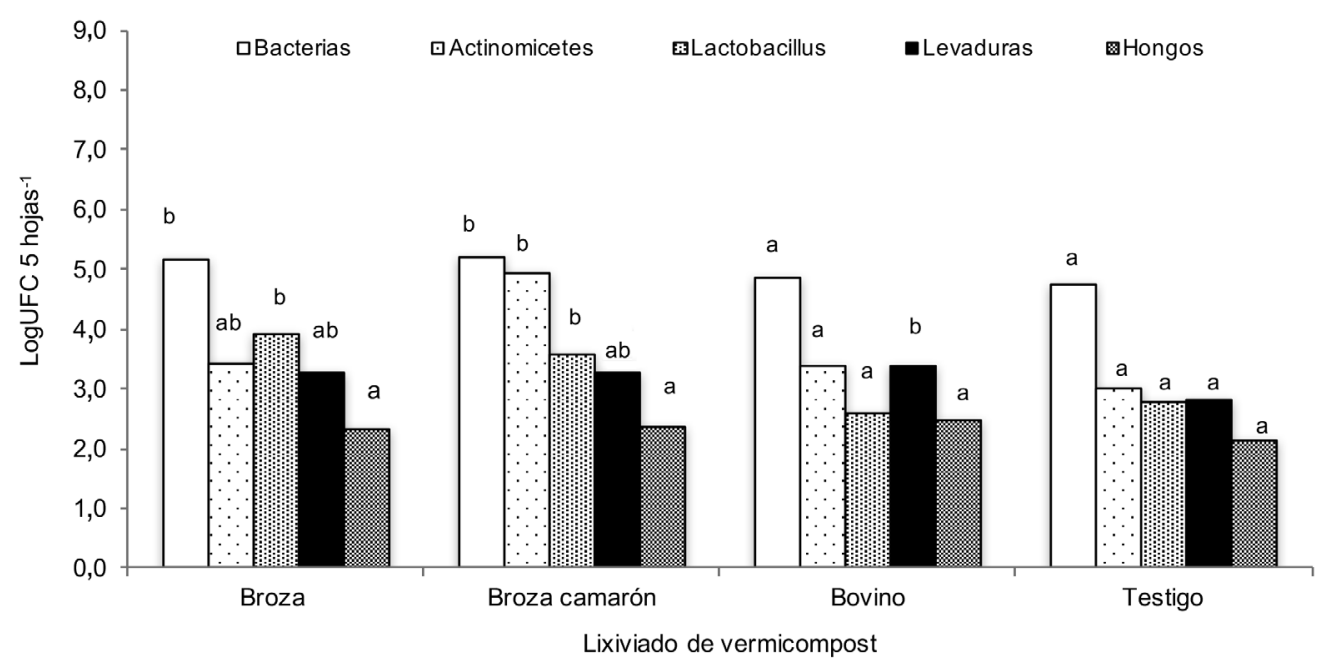

Fig. 4. Población de microorganismos en hojas de cafeto tratadas con lixiviados de vermicompost. 
La aplicación de los lixiviados de vermicompost sobre las hojas de cafeto no tuvo un efecto significativo sobre la incidencia, severidad y número de hojas con lesión (Cuadro 5), sin embargo, se observa una tendencia a un menor porcentaje de hojas enfermas en los tratamientos inoculados con los lixiviados de vermicompost de broza y de broza con camarón. Estos mismos tratamientos no presentaron lesiones con gemas, diferenciándose significativamente del testigo. Este efecto podría deberse a la presencia en los lixiviados de microorganismos antagonistas y químicos antimicrobianos (Litterick et al. 2004, Gutiérrez-Miceli et al. 2008).

Cuadro 5. Efecto de la aplicación de los lixivados de vermicompost de broza sobre el desarrollo de la enfermedad en hojas de cafeto.

\begin{tabular}{|c|c|c|c|c|c|c|}
\hline Lixiviado de vermicompost & $\begin{array}{c}\text { Incidencia* } \\
\%\end{array}$ & $\begin{array}{c}\text { Severidad* } \\
\%\end{array}$ & $\begin{array}{c}\text { Hojas con } \\
\text { lesión*** }\end{array}$ & Lesiones** & $\begin{array}{l}\text { Lesiones con } \\
\text { gemas** }\end{array}$ & Gemas/lesión** \\
\hline Broza café & $4 \mathrm{a}$ & $1,2 \mathrm{a}$ & $1,0 \mathrm{a}$ & $2,0 \mathrm{a}$ & $0,0 \mathrm{a}$ & $0,0 \mathrm{a}$ \\
\hline Broza camarón & 8 a & $0,8 \mathrm{a}$ & $2,6 \mathrm{a}$ & $2,6 \mathrm{a}$ & $0,0 \mathrm{a}$ & $0,0 \mathrm{a}$ \\
\hline Estiercol bovino & $16 \mathrm{a}$ & $1,3 \mathrm{a}$ & $5,4 \mathrm{a}$ & $6,0 \mathrm{a}$ & $0,4 \mathrm{ab}$ & $1,0 \mathrm{ab}$ \\
\hline Testigo & $24 \mathrm{a}$ & $0,8 \mathrm{a}$ & $5,6 \mathrm{a}$ & $5,6 \mathrm{a}$ & $1,6 \mathrm{~b}$ & $17,0 \mathrm{~b}$ \\
\hline
\end{tabular}

*Letras distintas indican diferencias significativas entre tratamientos $(\mathrm{p}<0,05)$.

** Letras distintas indican diferencias significativas entre tratamientos $(\mathrm{p}<0,10)$. Kruskall Wallis

Muchos de los géneros de microorganismos residentes en la superficie de las hojas presentan actividades de biocontrol que pueden reducir la enfermedad de las plantas (Barh et al. 2015). La adición de lactobacilos en los lixiviados a base de broza de café pudo afectar de manera negativa la presencia del hongo; estas bacterias se encuentran naturalmente en las superficies de las plantas y pueden competir por espacio y nutrientes o producir metabolitos secundarios.

Por otro lado, es posible que el alto $\mathrm{pH}$ encontrado en los lixiviados, contribuyó al efecto sobre la formación de gemas. Al respecto Mora et al. (1997), consideran entre las estrategias de control de Ojo de Gallo la alcalinización del medio con $\mathrm{NaOH}$, para lograr un $\mathrm{pH}$ superior a 8 en el caldo de atomización junto con la mezcla de fungicidas protectores y curativos aplicados. Los autores encontraron un mejor comportamiento en el combate del hongo cuando se utilizó el pH 8 con una mayor retención de hojas, una marcada disminución de la incidencia del patógeno y de la reinfección (control del inóculo secundario).

Ya que el uso de lixiviados de vermicompost de broza, broza con camarón y del té de vermicompost de estiércol bovino podrían tener un efecto inhibitorio sobre las cabecitas, es de gran importancia realizar estudios en planta a fin de determinar si estos productos pueden ser utilizados como inhibidores de la producción de gemas.

\section{AGRADECIMIENTOS}

La investigación fue financiada por los proyectos VI-733-A9-012 y VI-813-B1-551.

\section{LITERATURA CITADA}

Al-Mughrabi, KI; Bertheleme, C; Livingston, T; Burgoyne, A; Poirier, R; Vikram, A. 2008. Aerobic compost 
tea, compost and a combination of both reduce the severity of common Scab (Streptomyces scabiei) on Potato tubers. Journal of Plant Sciences 3(2):168-175.

Arancon, NQ; Edwards, CA; Dick, R; Dick, L. 2007. Vermicompost tea production and plant growth impacts. Biocycle 48:51-52.

Arauz, LF. 2011. Fitopatología un Enfoque Agroecológico. 2 ed. San José, Costa Rica, Editorial de la Universidad de Costa Rica. 519 p.

Artavia, S; Uribe, L; Saborío, F; Arauz, LF; Castro, L. 2010. Efecto de la aplicación de abonos orgánicos en la supresión de Pythium myriotylum en plantas de tiquizque (Xanthosoma sagittifolium). Agronomía Costarricense 34(1):17-29.

Barh, D; Khan, MS; Davies, E. 2015. Plant Omics: The omics of plant science. New Delhi, India, Springer. 825 p.

Barquero, M. 2007. Algunas consideraciones sobre el ojo de gallo. Revista informativa del Icafé I:11-15.

Barquero, M. 2012. Sistema de alerta temprana para el ojo de gallo. Revista informativa Icafé 2 6:2-4.

Blakeman, JP; Fokkema, NJ. 1982. Potential for biological combate of plant disease on the phylloplane. Annual Reviews Phytopathology 20:167-192.

Bollo, E. 1999. Lombricultura: una alternativa de reciclaje. Quito, Ecuador. Soboc Grafic. 149 p.

Carvajal, BF. 1939. Ojo de gallo (Omphalia flavida). Revista del Instituto de Defensa del Café de Costa Rica 7 (52):535-576

Castello, P; Celano, G; Zaccardelli, M. 2014. Metabolic patterns of bacterial communities in aerobic compost teas associated with potential biocontrol of soilborne plant diseases. Phytopathologia Mediterranea 53(2):277-286.

Castro, L; Flores, L; Uribe, L. 2011. Efecto del vermicompost y quitina sobre el control de Meloidogyne incognita en tomate a nivel de invernadero. Agronomía Costarricense 35(2):21-32.

Chaves, OC. 1996. Características biológicas del ojo de gallo (Mycena citricolor) en el cultivo del cafeto en Costa Rica y su control. Hojas divulgativas. San José, CR. Sandoz Agro S. A. 4 p.

Cohen, E. 2001. Chitin synthesis and inhibition: a revisit. Pest Managemente Science 57:946-950.

Di Rienzo, JA; Casanoves F; Balzarini, MG; Gonzalez, L; Tablada, M; Robledo, CW. INFOSTAT versión 2011. Grupo InfoStat, FCA, Universidad Nacional de Córdoba, Argentina. Disponible en http://www. infostat.com.ar

Diánez, F; Santos, M; Tello, JC. 2007. Suppressive effects of grape marc compost on phytopathogenic oomycetes. Archives of phytopathology and plant protection 40(1):1-18.

Domínguez, J; Edwards, E; Subler, S. 1997. A comparision of vermicomposting and composting. BioCycle 38(4):57-59.
Durán, L; Henríquez, C. 2007. Caracterización química, física y microbiológica de vermicompostes producidos a partir de cinco sustratos orgánicos. Agronomía Costarricense 31(1):41-51.

Echeverri, RJ. 1997. ¿Cómo vivir con el ojo de gallo? I Parte. Noticiero del Café Costa Rica 100:1-4.

Edwards, CA; Arancon, NQ; Greytak, S. 2006. Effects of vermicompost teas on plant growth and disease. Biocycle 47(5):28.

Farfán, DM; Gutiérrez, C. 2009. Determinación de la actividad quitinolítica de cepas nativas de actinomicetos y su efecto antagónico sobre microorganismos fitopatógenos. Tesis de grado Microbiología Ambiental. Pontificia Universidad Javeriana, Bogotá, Colombia. 154 p.

Ferruzi, C. 1994. Manual de lombricultura. Madrid, España, Mundi-Prensa. $137 \mathrm{p}$.

Fortis-Hernández, M; Leos-Rodríguez, JA; Preciado-Rangel, P; Orona-Castillo, I; García-Salazar, JA; GarcíaHernández, JL; Orozco-Vidal, JA. 2009. Aplicación de abonos orgánicos en la producción de maíz forrajero con riego por goteo. Terra Latinoamericana 27(4):329-336.

Fritz, JI; Franke-Whittle, IH; Haindl, S; Insam, H; Braun, R. 2012. Microbiological community analysis of vermicompost tea and its influence on the growth of vegetables and cereals. Canadian journal of microbiology 58(7):836-847.

García, RC; Dendooven, L; Gutierrez, FA. 2008. Vermicomposting leachate (Word Tea) as liquid fertilizer for maize (Zea mays L.) forage production. Assian Journal for Plant Sciencies 7(4):360-367.

Garg, VK; Gupta, R. 2009. Vermicomposting of agroindustrial processing waste. In Biotechnology for Agro-Industrial Residues Utilisation. Netherlands. Springer p. 431-456.

González, M. 2003. Cultivo in vitro de Ojo de gallo. Hoja Técnica. $\mathrm{N}^{\circ}$ 44. Manejo Integrado de Plagas y Agroecología (Costa Rica). (67):91-93.

Granados, MM. 2015. Estudio de la epidemiología y alternativas de manejo agroecológico del ojo de gallo (Mycena citricolor) en cafeto bajo sistemas agroforestales en Costa Rica. Sistema de Estudios de Posgrado, Programa de Doctorado en Sistemas de Producción Agrícola Tropical Sostenible. 205 p.

Gutiérrez-Miceli, FA; García-Gómez, RC; Rosales, RR; Abud-Archila, M, Angela, OLM; Cruz, MJG.; Dendooven, L. 2008. Formulation of a liquid fertilizer for sorghum (Sorghum bicolor (L.) Moench) using vermicompost leachate. Bioresource technology 99(14): 6174-6180.

Hoitink, HAJ; Stone, AG; Han, DJ. 1997. Supresión de enfermedades de plantas mediante compost Agronomía Costarricense 21(1):25-33. 
ICAFE (Instituto del Café de Costa Rica). 2011a. Guía Técnica para el Cultivo del Café. ICAFE-CICAFE. Heredia, Costa Rica. 2011. 72 p.

ICAFE (Instituto del Café de Costa Rica). 2011b. Informe sobre la actividad cafetalera de Costa Rica. Preparado en el Instituto del Café de Costa Rica para los Delegados al XL Congreso Nacional Cafetalero Ordinario San José, Costa Rica 4 de diciembre, 2011. 35 p.

INEC (Instituto Nacional de Estadística y Censos, Costa Rica). 2015. VI Censo Nacional Agropecuario 2014. Resultados generales. INEC-MAG. 42 p.

Larco, E. 2004. Preparación de lixiviados de compost y lombricompost. Hoja Técnica $\mathrm{N}^{\circ}$ 49. Manejo Integrado de Plagas y Agroecología (Costa Rica) $\mathrm{N}^{\circ}$ 73. 79-82 p.

Lazcano, C; Gómez-Brandón, M; Domíngez, J. 2008. Comparison of the effectiveness of composting and vermicomposting for the biological stabilization of cattle manure. Chemosphere 72:1013-1019.

Litterick, AM; Harrier, L; Wallace, P; Watson, CA; Wood, M. 2004. The role of uncomposted materials, composts, manures, and compost extracts in reducing pest and disease incidence and severity in sustainable temperate agricultural and horticultural crop production A Review. Critical Reviews in Plant Sciences 23(6):453-479.

López, LM. 1994. Uso de entomopatógenos y parasitoides como control biológico de plagas y enfermedades en el cultivo del café. MAG, Costa Rica. 97 p.

Lorch, HJ; Benckieser, G; Ottow, JCG. 1995. Basic methods for counting microorganisms in soil and water, pp 146-191. In: Alef, K; Nannipieri, P. (eds.). Methods in applied soil microbiology and biochemistry. Academic Press.

Mansour, FS; El-Sayed, GAM. 2011. Soil amendment and seed treatments with compost tea as alternative fungicide for controlling root rot disease of bean plants. Egyptian Journal of Biological Pest Control 21(1):19-26.

Marín, F; Dianez, F; Santos, M; Carretero, F; Castañeda, C; Navarro, MJ. 2014. Control of Phytophthora capsici and Phytophthora parasitica on pepper (Capsicum annuum L.) with compost teas from different sources, and their effects on plant growth promotion. Phytopathologia Mediterranea 53(2):216-228.

Marín, F; Santos, M; Diánez, F; Carretero, F; Gea, FJ; Yau, JA; Navarro, MJ. 2013. Characters of compost teas from different sources and their suppressive effect on fungal phytopathogens. World Journal of Microbiology and Biotechnology 29(8):1371-1382.

Mora, F. 1987. Combate Biológico del Ojo de Gallo (Mycena citricolor) Berk y Curt Saac, en café mediante bacterias antagonistas. Tesis Lic. San José, CR. UCR. 56 p.
Moreno-Caselles, J; Moral, R; Perez-Murcia, R; PerezEspinosa, A; Rufete, B. 2002. Nutrient value of animal manures in front of environmental hazards. Communications In Soil Science And Plant Analysis 33(15-18):3023-3032.

Nath, G; Singh, K; Singh, DK. 2009. Chemical analysis of vermicomposts/vermiwash of different combinations of animal, agro and kitchen wastes. Australian Journal of Basic and Applied Sciences 3(4):36723676.

Oka, Y. 2010. Mechanisms of nematode supression by organic soil amendment. A review. Applied Soil Ecology 44(2):101-115.

Osorio, L.; Patiño, LF; Bustamante, E; Rodríguez, P. 2004. Selección y evaluación de bacterias quitinolíticas provenientes de la zona de Urabá, para el control de la Sigatoka Negra. Boletín Técnico de Cenibanano 6:8-13.

Otero, O. 2010. Producción y evaluación de vermicomposta en Hormigueros Sierra Nanchititla, México. Tesis de Lic. Ciencias Ambientales. México. Universidad Autónoma del Estado de México. 52 p.

Paul, E.; Clark, F. 1996. Soil microbiology and biochemistry. 2 ed. San Diego, CA, USA, Academic Press. 340 p.

Preciado, P; Fortis, M; Garcia, JL; Rueda, E; Esparza, JR; Lara, A; Segura, MA; Orozco, J. 2011. Evaluación de soluciones nutritivas orgánicas en la producción de tomate en invernadero. Interciencia 36(9):689-693.

PROCOMER (Promotora Comercio Exterior, Costa Rica). 2015. Estadísticas de comercio exterior de Costa Rica 2014. PROCOMER. 239 p.

Rao, DV; Tewari, JP. 1988. Suppression of the symptoms of American leaf spot of coffee with calcium hydroxide. Plant disease 72(8):688-690.

Rodríguez, E; Gamboa, MM; Hernández, F; García, JD. 2005. Bacteriología General. San José, Costa Rica, Editorial Universidad de Costa Rica. 370 p.

Rodriguez, R; Morgan, G. 1987. Biological control of nematodes: Soil amendments and microbial antagonist. Plant and Soil (100):237-247.

Salazar, LM; Patiño, LF; Bustamante, E. 2006. Sustratos foliares para el incremento de bacterias quitinolíticas y glucanolíticas en la filosfera de banano. Revista Facultad Nacional de agronomía-Medellín 59(2):3449-3465.

Sastoque, L; Mercad, M; Martínez, MM; Quevedo, B; Pedroz, AM. 2007. Producción de quitinasas extracelulares con una cepa alcalófila halotolerante de Streptomyces sp., aislada de residuos de camarón. Revista Mexicana de Ingeniería Química 6(2):137146.

Scheuerell, SJ; Mahaffee, W. 2002. Compost tea: principles and prospects for plant disease control. Compost Science and Utilization 10(4):313-338. 
Scheuerell, SJ. 2003. Understanding how compost tea can control disease. Biocycle Journal of composting and organic recycling. BioCycle 44(2):20-26.

Scheuerell, SJ; Mahaffee, WF. 2004. Compost tea as a container medium drench for suppressing seedling damping-off caused by Pythium ultimum. Phytopathology 94(11):1156-1163.

Scheuerell, SJ; Mahaffee, WF. 2006. Variability associated with suppression of gray mold (Botrytis cinerea) on geranium by foliar applications of nonaerated and aerated compost teas. Plant Disease 90(9):1201-1208.

Siles, J. 1997. Producción de abono orgánico con pulpa de café mediante el lombricompostaje. CATIE. Postgrado, Turrialba, Costa Rica. 93 p.

Soil And Plant Analysis Council. 1998. Handbook of Reference Methods for Plant Analysis. Ed. K Yash. CRC Press. Washington DC. 320 p.

Tewari, JP. 1990. Mecanismo de patogénesis del ojo de gallo causado por Mycena citricolor. Taller regional sobre roya, ojo de gallo y otras enfermedades del cafeto. Resúmenes IICA-PROMECAFE, Costa Rica. 48 p.

TMECC (Test methods for the examination of composting and compost, USA). 2002. The Composting Council Research and Education Foundation. Disponible en: http://www.compostingcouncil.org

Uribe, L; Arauz, LF; Mata, M; Meneses, G; Castro, L. 2009. Efecto del vermicompostaje sobre las poblaciones de Colletotrichum acutatum y Pectobacterium carotovorum presentes en residuos de plantas. Agronomía Costarricense 33(1):91-101.

Vargas, E; Vargas, A; Umaña, G; Gonzalez, M. 1990. Descripción de Mycena citricolor (Berk. y Curt) Sacc. Taller Regional sobre roya, ojo de gallo y otras enfermedades del cafeto. San José, CR, UCR. 48 p.
Vargas, E. 1996. Opciones al uso de fungicidas en el combate del ojo de gallo en café. In: Memoria X Congreso Nacional Agronómico y de Recursos Naturales, III Congreso Nacional de Fitopatología, II Congreso Nacional de Suelos. San José, Costa Rica. Editorial EUNED. Volumen II. pp 3-6.

Vargas, LG. 2004. Bases epidemiológicas para el desarrollo de un sistema de pronóstico en Ojo de Gallo (Mycena citricolor Berk. Y Curt) Sacc. en cafeto (Coffea arabica). Tesis MSc. San José, CR. UCR. 118 p.

Villegas, W. 2011. Caficultores se preparan ante el cambio climático. Revista informativa ICAFE I-2011 5 (1):7-8.

Wang, A; Arauz, LF. 1999. Aplicación de principios epidemiológicos para el combate de ojo de gallo en cafeto. In Memoria XI congreso Agronómico/IV congreso Nacional de Fitopatología. p. 9-12.

Wang, A; Avelino, J. 1999. El ojo de gallo del cafeto Mycena citricolor. In Desafíos de la caficultura en Centroamérica. Centro de Ivestigación en Protección de Cultivos, Universidad de Costa Rica. Centre de Cooperatio Internationale en Recherche Agronomique pour le Developpement, France. IICAPROMECAFE. Bertrand, B; Rapidel, B. (eds.). p 243-260.

Wobbrock, JO; Findlater, L; Gergle, D; Higgins, JJ. 2011. The aligned rank transform for nonparametric factorial analyses using only anova procedures. In Proceedings of the SIGCHI Conference on Human Factors in Computing Systems p. 143-146. ACM.

Wollum, AG. 1982. Cultural methods for soil microorganisms. In: Page, AL; Miller, R.H; Keeney, KR (eds.). Methods of soil analysis. Part 2. Chemical and microbiological properties. pp. 781-802. ASA y SSSA.

Todos los derechos reservados. Universidad de Costa Rica. Este artículo se encuentra licenciado con Creative Commons Reconocimiento-NoComercial-SinObraDerivada 3.0 Costa Rica. Para mayor información escribir a rac.cia@ucr.ac.cr 
